\title{
Đặc điểm sinh học, sinh thái của loài Hoàng liên ô rô lá dày (Mahonia bealei (Fortune) Pynaert) ở Việt Nam
}

\author{
Bùi Văn Hướng ${ }^{1}$, Ngô Đức Phương ${ }^{2}$, Nguyễn Trung Thành ${ }^{2}$ \\ Trần Văn Tú ${ }^{3}$, Nguyễn Thái Sơn ${ }^{3}$, Nguyễn Thị Vân $\mathrm{Anh}^{4}$, Bùi Văn Thanh ${ }^{4, *}$ \\ ${ }^{1}$ Bảo tàng Thiên nhiên Việt Nam, Viện Hàn lâm Khoa học và Công nghệ Việt Nam, \\ 18 Hoàng Quốc Việt, Hà Nội, Việt Nam \\ ${ }^{2}$ Truòng Đại học Khoa học Tư nhiên, ĐHQGHN, 334 Nguyễn Trãi, Hà Nội, Việt Nam \\ ${ }^{3}$ Vườn Quốc gia Hoàng Liên \\ ${ }^{4}$ Viện Sinh thái và Tài nguyên sinh vật, Viện Hàn lâm Khoa học và Công nghệ Việt Nam, \\ 18 Hoàng Quốc Việt, Hà Nội, Việt Nam \\ Nhận ngày 20 tháng 12 năm 2016 \\ Chỉnh sửa ngày 22 tháng 3 năm 2017; Chấp nhận đăng ngày 28 tháng 6 năm 2017
}

\begin{abstract}
Tóm tắt: Hoàng liên ô rô lá dày (Mahonia bealei (Fortune) Pynaert) (Berberidaceae) là một loài cây thuốc có giá trị cao, loài được ghi nhận có phân bố tự nhiên tại huyện Sa Pa, Bát Xát tỉnh Lào Cai và huyện Quản Bạ tỉnh Hà Giang. Loài này đang bị khai thác mạnh và bị đe dọa nghiêm trọng trong tự nhiên, được đưa vào Sách đỏ Việt Nam, năm 2007 ở mức EN;

Hoàng liên ô rô lá dày là cây bụi, có chiều cao từ $0,5-2(-4) m$. Lá kép lông chim 1 lần lẻ, kích thước lá $25-40 \times 8-13 \mathrm{~cm}, 8-14$ cặp lá chét, mép lá chét thường có răng cưa nhọn; Cụm hoa mọc thẳng đứng với $3-15$ chùm, dài $7-26 \mathrm{~cm}$. Quả mọng, hình dục $1,1-1,4 \times 0,8-1,0 \mathrm{~cm}$, mỗi quả mang 1 - 2 hạt; hạt kích thước 0,6 - 0,8 x 0,4 - 0,5cm;

- Cây tái sinh chủ yếu từ hạt; mật độ cây trưởng thành (từ $0,5 \mathrm{~m}$ trở lên) trong khoảng 418 -512 cá thể/ha tại khu vực nghiên cứu. Thời gian ra chồi mới, lá non tập trung vào các tháng từ tháng 7 đến tháng 10 hàng năm, chiều cao tăng trưởng $11,73 \mathrm{~cm} /$ năm.

- Hoàng liên ô rô lá dày thường mọc dưới tán rừng thưa hay các trảng cây bụi trên núi đá vôi nơi đất có lượng mùn ít, nghèo dinh dưỡng, độ cao từ $1.700-2.500 \mathrm{~m}$, nhiệt độ trung bình khoảng 15 $16^{\circ} \mathrm{C}$, độ ẩm không khí trên $80 \%$, lượng mưa $1.800-2.800 \mathrm{~mm} /$ năm.
\end{abstract}

Tù khóa: Mahonia bealei, cây thuốc, sinh học, sinh thái.

\section{1. Đặt vấn đề}

Hoàng liên ô rô lá dày (Mahonia bealei (Fortune) Pynaert) thuộc họ Hoàng liên ô rô (Berberidaceae) đây là loài được sử dụng để

\footnotetext{
*Tác giả liên hệ. ĐT.: 84-912011765.

Email: thanhbv2001@gmail.com

https://doi.org/10.25073/2588-1140/vnunst.4497
}

làm dược liệu do có hàm lượng Berberin cao và được buôn bán ở nhiều nơi với tên gọi cây Mật gấu $[1,2]$. Chi Mahonia Nutt. gồm các đại diện là cây bụi hay gỗ nhỏ, phân bố ở vùng ôn đới ẩm hoặc cận nhiệt đới châu Á, bao gồm Trung Quốc, Nê Pan, Ần Độ và một số nước khác ở vùng Trung Á. Ở Việt Nam, chi Mahonia có 3 loài gồm Mahonia bealei, M. japonica và $M$. nepalensis [3-5]. Loài Hoàng liên ô rô lá dày 
(Mahonia bealei) được coi là bị đe dọa ở mức độ cao nhất so với các loài khác cùng chi do số lượng cá thể trong tự nhiên còn quá ít bởi tình trạng khai thác mạnh [6]. Vì vậy, nghiên cứu về một số đặc điểm sinh học, sinh thái của cây thuốc quý này sẽ góp phần bảo tồn và phát triển chúng trong tương lai.

\section{2. Đối tượng, phương pháp nghiên cứu}

\section{Đối tượng và phạm vi nghiên cưu}

Đối tượng nghiên cứu là loài Hoàng liên ô rô lá dày (Mahonia bealei (Fortune) Pynaert).

Phạm vi nghiên cứu là loài Hoàng liên ô rô lá dày phân bố tại huyện Bát Xát và huyện $\mathrm{Sa}$ $\mathrm{Pa}$, tỉnh Lào Cai.

\section{Phuoong pháp nghiên cúu}

- Phurong pháp kế thùa: Kế thừa các tài liệu nghiên cứu về phân bố, sinh học, sinh thái và tri thức sử dụng của người dân bản địa có liên quan đến cây Hoàng liên ô rô lá dày.

- Phuoong pháp điều tra phỏng vấn: Phỏng vấn người dân địa phương kết hợp với điều tra theo tuyến để xác định các khu vực có thể có loài Hoàng liên ô rô lá dày phân bố; thu thập thông tin từ những người thường xuyên khai thác để bán cũng như thông tin từ chính quyền địa phương để đánh giá mức độ khai thác từ trước đến nay [7].

- Phuoong pháp nghiên cứu sinh học: Sử dụng các phương pháp nghiên cứu Thực vật học của Nguyễn Nghĩa Thìn [8]; các phương pháp nghiên cứu Thực vật dân tộc học, cây thuốc của Nguyễn Bá Ngãi [7], Nguyễn Thượng Dong và cs. [9], Gary J. Martin [10] ... Sự sinh trưởng, phát triển và các đặc điểm sinh học được xác định bằng việc theo dõi tăng trưởng theo chiều cao của từng cá thể/năm, thẽo dõi mùa hoa quả, số lượng quả, hạt, thời gian nảy mầm trong tự nhiên. Nghiên cứu mật độ dựa vào ô tiêu chuẩn (OTC), tùy điều kiện cụ thể để lập các OTC $20 \times 20 \mathrm{~m}$ hoặc $10 \times 10 \mathrm{~m}$ đối với cây trưởng thành và $5 \times 5 \mathrm{~m}$ đối với cây tái sinh.
- Phuoong pháp nghiên cứu sinh thái: Xác định một số yếu tố sinh thái - môi trường như độ ẩm, cường độ ánh sáng, nhiệt độ, lượng mưa, nhiệt độ trung bình ngày, trung bình năm,... kết hợp giữa đo trực tiếp và thu thập các số liệu khí tượng thủy văn tại địa phương; Xác định các loài thực vật chủ yếu cùng sinh sống với loài Hoàng liên ô rô lá dày [11].

- Phuoong pháp xủ lý số liệu: Số liệu thu thập được tổng hợp, xử lý số liệu bằng phần mềm Excel làm cơ sở để phân tích và đánh giá kết quả.

\section{Kết quả nghiên cứu}

\section{Đặc điểm sinh học loài Hoàng liên ô rô lá dày}

\section{Đặc diểm hình thái loài Hoàng liên ô rô lá dày}

Qua kết quả nghiên cứu đặc điểm sinh học ta thấy Hoàng liên Ô rô lá dày là cây bụi, cao 0,5 - 2(-4)m. Lá kép lông chim 1 lần lẻ, mặt trên màu lục xám nhẹ, mặt dưới đôi khi có màu xanh lục hơi vàng nhạt, thuôn dài, kích thước $25-40 \times 8-13 \mathrm{~cm}$, với $8-14$ cặp lá chét. Lá chét thường dày, cứng, cặp lá chét dưới cùng hình trứng có kích thước $1-3 \times 1-2 \mathrm{~cm}$, có 1 2 răng ở mỗi bên mép lá. Các lá chét phía trên có dạng hình trứng hay hình thuôn có kích thước $3-6 \times 2-4 \mathrm{~cm}$, mép có 2 - 6 răng mỗi bên, gốc lá chét hình tròn, xiên, đôi khi có dạng hình tim, đầu lá chét nhọn; lá chét tận cùng lớn hơn, kích thước $4-9 \times 3-4,5 \mathrm{~cm}$, cuống dài $1-6 \mathrm{~cm}$.

Cụm hoa mọc thẳng đứng với 3 - 15 chùm, dài $7-26 \mathrm{~cm}$. Lá bắc ở gốc cụm hoa hình trứng đến hình mác, kích thước $1,5-4$ x $0,7-1,2 \mathrm{~cm}$. Cuống hoa dài $4-6 \mathrm{~mm}$; lá bắc hình trứng rộng hay hình mác dạng trứng, kích thước $3-5 \times 2-$ $3 \mathrm{~mm}$, đầu tù. Đài hoa màu vàng, xếp thành 3 vòng; các lá đài phía ngoài hình trứng, kích thước $2,3-2,5 \times 1,5-2,5 \mathrm{~mm}$; các lá đài ở giữa hình elip, kích thước 5 - 6 x 3,5 - 4mm; các lá đài phía trong cùng hình elip thuôn, kích thước $6,5-7$ x $4-4,5 \mathrm{~mm}$. Cánh hoa hình elip dạng trứng ngược, kích thước $6-7 \times 3-4 \mathrm{~mm}$, gốc có 
các tuyến rõ ràng, đầu hơi có răng cưa, với các thùy tròn. Nhị hoa có kích thước 3,2 - 4,5mm; bao phấn dính nhau $1,1-1,3 \mathrm{~mm}$, tròn hay cụt (bằng). Bầu thuôn hình trứng, dài $3,2 \mathrm{~mm}$; noãn 3 - 4; vòi nhụy ngắn.

Mỗi thân cây mang 5 - 7 chùm quả, mỗi chùm quả mang từ $22-50$ quả, tập trung nhiều nhất là khoảng 30 - 35 quả/chùm. Quả mọng, hình bầu dục, kích thước khoảng $1,1-1,4$ x 0,8
- 1,0cm; chín có màu tím đậm, bề mặt phủ phấn trắng. Vòi nhụy gần như không tồn tại. Mỗi quả mang 1 - 2 hạt, kích thước 0,6 - 0,8 x $0,4-0,5 \mathrm{~cm}$; trong đó số quả mang 2 hạt chiếm khoảng 70\%; khổi lượng 100 hạt là $5,28 \mathrm{~g}$ (độ ẩm $44,67 \%$ ) .

Qua quá trình theo dõi và đo đếm ở thời điểm quả già và chín cho thấy quá trình chín của quả kéo dài, rải rác từ tháng 4 đến tháng 6 .
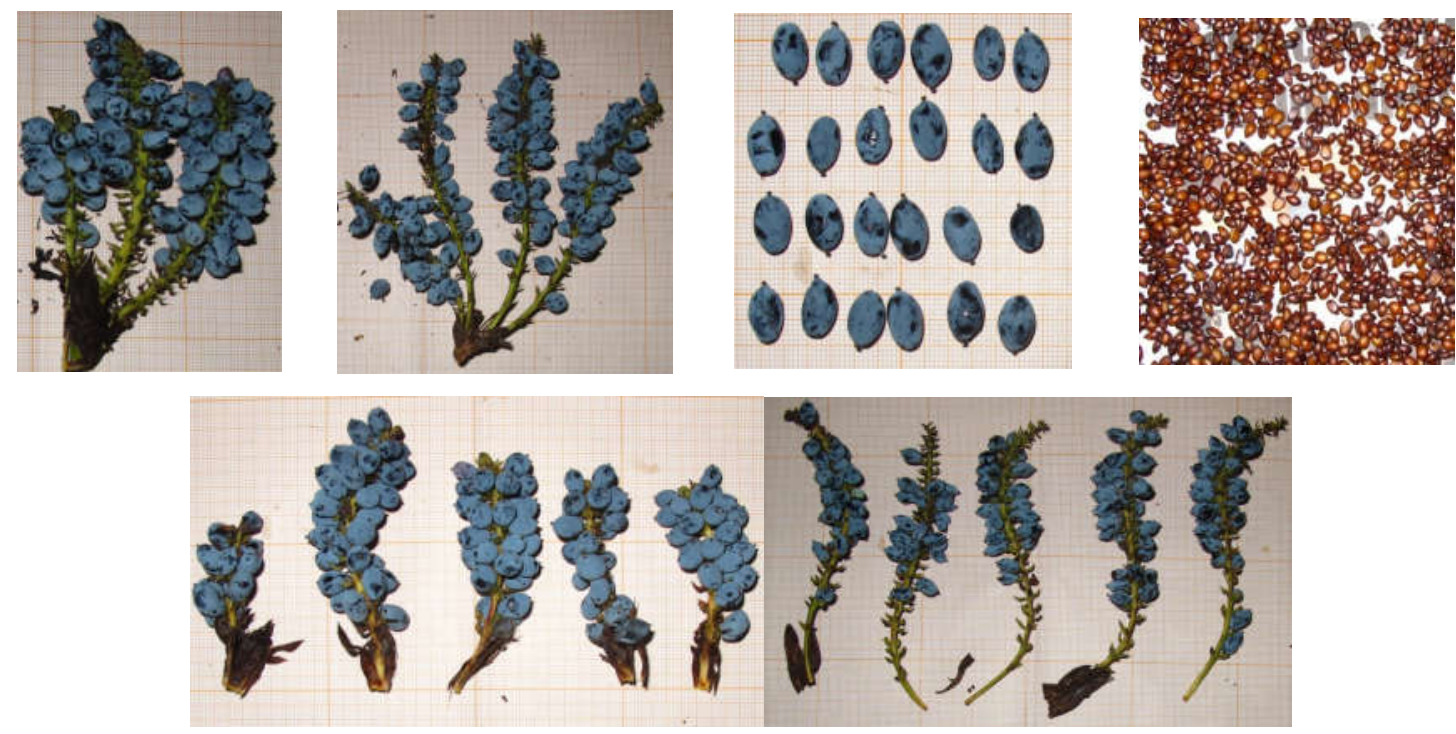

Hình 1. Đặc điểm hình thái quả và hạt loài Hoàng liên ô rô lá dày.

Đặc điểm sinh trưởng và tái sinh và mật độ của Hoàng liên ô rô lá dày

Trong thời kỳ cuối của giai đoạn quả chín bắt đầu xuất hiện các chồi non, chồi non của
Hoàng liên ô rô lá dày thường mọc tập trung ở ngọn, được bao bởi các bao chồi màu xanh vàng, mép hơi đỏ, và thường chỉ có 1 chồi.

Bảng 1. Các chỉ tiêu đặc điểm hình thái của loài Hoàng liên ô rô lá dày (Mahonia bealei)

\begin{tabular}{llll}
\hline Chỉ tiêu theo dõi & Kích thước/ số lượng & Chỉ tiêu theo dõi & Kích thước/ số lượng \\
\hline Chiều cao thân $(\mathrm{cm})$ & $103,23 \pm 54,62$ & Số hoa/ chùm & $90,03 \pm 17,07$ \\
Đường kính thân $(\mathrm{cm})$ & $1.42 \pm 0.30$ & Số quả/ chùm & $32,06 \pm 7,52$ \\
Chiều dài lá $(\mathrm{cm})$ & $30,29 \pm 5,09$ & Chiều dài quả $(\mathrm{mm})$ & $12,90 \pm 1,12$ \\
Chiều rộng lá $(\mathrm{cm})$ & $9,54 \pm 1,54$ & Chiều rộng quả $(\mathrm{mm})$ & $9,17 \pm 0,88$ \\
Số lá chét/ lá & $23,67 \pm 2,37$ & Khối lượng quả $(100$ quả tươi) $)(\mathrm{g})$ & $39,03 \pm 5,50$ \\
Chiều dài lá chét $(\mathrm{cm})$ & $3,96 \pm 1,30$ & Số hạt/ quả & $1,74 \pm 0,44$ \\
Chiều rộng lá chét $(\mathrm{cm})$ & $2,20 \pm 0,67$ & Chiều dài hạt $(\mathrm{mm})$ & $7,25 \pm 0,52$ \\
Số chùm hoa/ đỉnh $\sinh$ & $9,83 \pm 1,87$ & Chiều rộng hạt $(\mathrm{mm})$ & $4,70 \pm 0,40$ \\
trưởng & & &
\end{tabular}




\begin{tabular}{|c|c|}
\hline Chiều dài chùm quả (cm) & $\begin{array}{l}\text { Khối lượng hạt-100 hạt }(\mathrm{g}) \text {, tại } 5,28 \pm 0,31 \\
\text { độ ẩm } 44,67 \%\end{array}$ \\
\hline $\begin{array}{l}\text { Thời điểm ra chồi mới, ra lá non và lá } \\
\text { trưởng thành tập trung vào các tháng từ tháng } 7\end{array}$ & $\begin{array}{l}\text { trung bình } 11,73 \pm 4,19 \mathrm{~cm} \text { (biến động từ } 8 \text { - } \\
15 \mathrm{~cm} \text { ) }\end{array}$ \\
\hline $\begin{array}{l}\text { đến tháng } 10 \text { hàng năm. Vào đầu mùa sinh sản } \\
\text { (khoảng tháng } 1-2 \text { dương lịch), một số đỉnh } \\
\text { sinh trưởng xuất hiện các chồi hoa nhưng } \\
\text { không có thêm các lá mới và không tăng trưởng } \\
\text { chiều cao; những đỉnh sinh trưởng không ra hoa } \\
\text { thì giữ nguyên. Cây sinh trưởng chậm nên chiều }\end{array}$ & $\begin{array}{l}\text { Trong tự nhiên, Hoàng liên ô rô lá dày tái } \\
\text { sinh chủ yều từ hạt. Cây ra hoa, quả nhiều, mật } \\
\text { độ cây con (cây có chiều cao dưới } 0,5 \mathrm{~m} \text { và cây } \\
\text { chỉ có lá mầm) lớn. Trong thử nghiệm sơ bộ vế } \\
\text { khả năng nảy mầm của hạt khi gieo trực tiếp } \\
\text { vào đất, chúng tôi thấy tỵ lệ nảy mầm đạt tới }\end{array}$ \\
\hline
\end{tabular}

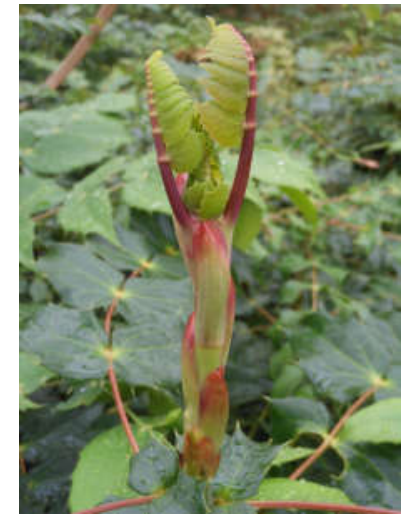

(A) Sự hình thành chồi mới.

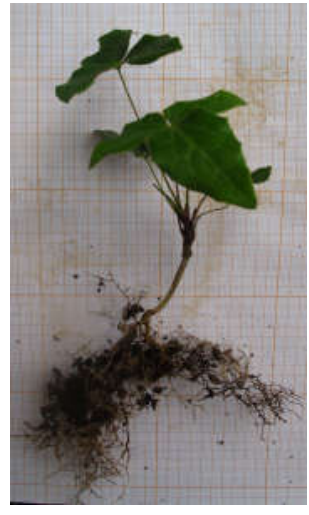

(B) Cây tái sinh ngoài tự nhiên.

Hình 2. Quá trình sinh trưởng và tái sinh của cây Hoàng liên ô rô lá dày.

Mật độ loài được xác định tại hai khu vực phân bố ở huyện Bát Xát và $\mathrm{Sa} \mathrm{Pa}$, tỉnh Lào Cai. Kết quả đánh giá 22 OTC kích thước $20 \times 20 \mathrm{~m}$ và 25 OTC kích thước $10 \times 10 \mathrm{~m}$ dối với cây trưởng thành, cây có chiều cao từ $0,5 \mathrm{~m}$ trở lên và $30 \mathrm{OTC}$ kích thước $5 \times 5 \mathrm{~m}$ đối với cây dưới $0,5 \mathrm{~m}$ (chỉ tính cây có lá thật) được thể hiện trong bảng 2 .

Bảng 2. Mật độ các thể loài Hoàng liên ô rô lá dày.

\begin{tabular}{llll}
\hline TT & $\begin{array}{l}\text { Kích } \\
\text { thước } \\
\text { ô tiêu } \\
\text { chuẩn }\end{array}$ & $\begin{array}{l}\text { Số cá thể } \\
\text { trung bình }\end{array}$ & $\begin{array}{l}\text { Số cá } \\
\text { thể/ha }\end{array}$ \\
\hline 1 & $20 \times 20 \mathrm{~m}$ & $16,73 \pm 7,60$ & 418,18 \\
2 & $10 \times 10 \mathrm{~m}$ & $5,12 \pm 2,82$ & 512,00 \\
3 & $5 \times 5 \mathrm{~m}$ & $53,73 \pm 39,28$ & $21.493,33$ \\
\hline
\end{tabular}

Mật độ cây tái sinh và cây thấp dưới $0,5 \mathrm{~m}$ là rất lớn, tới trên $21.493,33$ cá thể/ha nhưng số cá thể trưởng thành hoặc có chiều cao trên 0,5 $\mathrm{m}$ chỉ có 418-512 cá thể/ha. Thực tế cho thấy, hạt của loài Hoàng liên ô rô lá dày có tỷ lệ nảy mầm cao, lượng hạt lớn nên khi gặp điều kiện thuận lợi có thể nảy mầm và hình thành cây con rất nhiều; tuy nhiên tại các khu vực phân bố loài này có điều kiện thời tiết biến động lớn về cường độ ánh sáng, độ ẩm, nhiệt độ... do đó sau một thời gian nhất định, phần lớn cây tái sinh sẽ bị khô và chết; Một nguyên nhân khác là do cây tái sinh dễ bị tác động từ các loài động vật, côn trùng, cạnh tranh ánh sáng hoặc các yếu tố vật lý khác, do đó chỉ có một tỷ lệ rất nhỏ cây sinh trưởng và trưởng thành được. 

lá dày

Đặc điểm sinh thái loài Hoàng liên ô rô

Mối quan hệ giữa các yếu tố tự nhiên và sự phân bố của Hoàng liên ô rô lá dày

Qua điều tra, nghiên cứu mới chỉ phát hiện loài Hoàng liên ô rô lá dày có phân bố tại huyện Bát Xát và huyện $\mathrm{Sa} \mathrm{Pa}$, tỉnh Lào Cai. Một số nơi thuộc tỉnh Hà Giang (Đồng Văn, Quản Bạ) trước đây đã được ghi nhận có mặt loài này nhưng đến nay chưa tìm lại được. Tuy nhiên, điều đó vẫn chưa đủ cơ sở để khẳng định loài Hoàng liên ô rô lá dày không còn tồn tại trong tự nhiên tại Hà Giang.

Cây thường mọc dưới tán rừng thưa và vách núi đá vôi, trảng cây bụi hoặc khe suối cạn ven núi đá; đây là những nơi đất có lượng mùn ít, nghèo dinh dưỡng, độ cao từ $1.800-2.500 \mathrm{~m}$. Những nơi này thường có độ ẩm, nhiệt độ và cường độ ánh sáng biến thiên mạnh.

Nhiệt độ trung bình năm là $15-16^{\circ} \mathrm{C}$, vào mùa Đông, hầu như năm nào ở điểm phân bố tại huyện Bát Xát (có độ cao 2.200 - 2.500m) cũng có băng tuyết; vào mùa hè, nhiệt độ có thể lên tới $30-32^{\circ} \mathrm{C}$. Vào mùa mưa ẩm, ở cả hai điểm phân bố, độ ẩm rất cao, thậm chí có thể bão hòa $(100 \%)$. Về cường độ ánh sáng cũng có sự biến thiên rất lớn, Cường độ ánh sáng biến thiên mạnh từ $0,26 \times 10^{3} 1 \mathrm{x}$ vào ngày có mù dày đặc và lên đến $112,9 \times 10^{3} \mathrm{~lx}$ khi trời nắng gắt, không có mây (số liệu đo trong khoảng thời gian từ $11 \mathrm{~h}-13 \mathrm{~h}$ ).

Bảng 3. Đặc điểm tự nhiên tại khu vực Hoàng liên ô rô lá dày phân bố

\begin{tabular}{|c|c|}
\hline Độ cao (m) & $1.700-2.500$ \\
\hline $\begin{array}{l}\text { Nhiệt độ trung bình } \\
\left({ }^{\circ} \mathrm{C}\right)\end{array}$ & $15-16(-5-32)$ \\
\hline $\begin{array}{l}\text { Độ ẩm không khí trung } \\
\text { bình }(\%)\end{array}$ & $>80(50-100)$ \\
\hline $\begin{array}{l}\text { Lượng mưa trung bình } \\
\text { (mm/năm) }\end{array}$ & $1.800-2.800$ \\
\hline Cường độ ánh sáng (1x) & $0,26 \times 10^{3}-112,9 \times 10^{3}$ \\
\hline
\end{tabular}

Mối quan hệ giũ̃a các loài thực vật với loài Hoàng liên Ô rô lá dày

Tại các địa điểm nghiên cứu quan sát, Hoàng liên Ô rô lá dày thường hiện diện ở các khu rừng có thành phần quần xã thực vật tương đối đơn giản. Các loài phân bố thường là các loài điển hình, đặc trưng cho các vùng đỉnh núi đá vôi phía Bắc. Tầng cây gỗ gồm các loài như: Tống quán sủ (Alnus nepalensis), Chân chim (Schefflera sp.), Chẹo (Engelhardia sp.),... Tầng cây bụi gồm các loài chính như: Ngũ sắc, Đùm đũm,... có chiều cao trung bình từ $1-2 \mathrm{~m}$. Tầng thảm tươi chủ yếu là các loài: Cỏ lào tím, Cỏ lá tre, Rau răm... có phân bố thưa.

Bảng 4. Các loài thực vật chủ yếu tại các điểm nghiên cứu có loài Hoàng liên Ô rô lá dày phân bố

\begin{tabular}{lllll}
\hline \multirow{2}{*}{ STT } & \multirow{2}{*}{ Dạng sống } & Tên loài & & \\
\cline { 3 - 4 } & & Tên Việt Nam & Tên Khoa học & \\
\hline 1 & Tống quán sủ & Alnus nepalensis & Betulaceae \\
2 & \multirow{2}{*}{ Cây gỗ } & Chân chim & Schefflera sp. & Araliaceae \\
3 & Chẹo & Engelhardia sp. & Juglandaceae \\
4 & & Kháo nhậm & Machilus odoratissima & Lauraceae \\
\hline 5 & Ngũ sắc & Ageratum conyzoides & Asteraceae \\
6 & Đum không đổi & Rubus etropicus & Rosaceae \\
7 & Gối hạc & Leea indica & Leeaceae \\
8 & Cây bụi & Mua & Melastoma sp. & Melastomataceae \\
9 & & Thành ngạnh & Cratoxylon formosum & Hypericaceae \\
10 & & Hoàng liên ba gai & Berberis wallichiana & Berberidaceae \\
\hline
\end{tabular}




\begin{tabular}{|c|c|c|c|c|}
\hline 11 & \multirow{6}{*}{ Thảm tươi } & Dương xỉ & Pteris sp. & Pteridoiceae \\
\hline 12 & & Thông đất & Lycopodiella cernua & Lycopodiaceae \\
\hline 13 & & Cỏ lào tím & Eupatorium coelestinum & Asteraceae \\
\hline 14 & & Cỏ lá tre & Lophatherum gracile & Poaceae \\
\hline 15 & & Rau răm & Polygonum sp. & Polygonaceae \\
\hline 16 & & Khoai nước & Colocasia esculenta & Araceae \\
\hline
\end{tabular}

\section{Kết luận}

- Hoàng liên ô rô lá dày là cây bụi, có chiều cao từ $0,5-2(-4) \mathrm{m}$. Lá kép lông chim 1 lần lẻ, kích thước lá $25-40 \times 8-13 \mathrm{~cm}, 8-14$ cặp lá chét, mép lá chét thường có răng cưa nhọn; Cụm hoa mọc thẳng đứng với 3 - 15 chùm, dài 7 - 26cm. Quả mọng, hình dục 1,1 - 1,4 x 0,8 $1,0 \mathrm{~cm}$, mỗi quả mang 1 - 2 hạt; hạt kích thước $0,6-0,8 \times 0,4-0,5 \mathrm{~cm}$; khối lượng 100 hạt khối lượng 100 hạt là 5,28g (độ ẩm 44,67\%).

- Cây tái sinh chủ yếu từ hạt; mật độ cây trưởng thành (từ $0,5 \mathrm{~m}$ trở lên) trong khoảng 418-512 cá thể/ha tại khu vực nghiên cứu. Thời gian ra chồi mới, lá non và lá trưởng thành tập trung vào các tháng từ tháng 7 đến tháng 10 hàng năm. Mỗi lần sinh trưởng của cây chỉ đạt chiều cao $11,73 \pm 4,19 \mathrm{~cm}$.

- Hoàng liên ô rô lá dày thường mọc dưới tán rừng thưa hay các trảng cây bụi trên núi đá vôi nơi đất có lượng mùn ít, nghèo dinh dưỡng, độ cao từ $1.800-2.500 \mathrm{~m}$, nhiệt độ trung bình khoảng $15-16^{\circ} \mathrm{C}$, độ ẩm không khí trên $80 \%$, lượng mưa $1.800-2.800 \mathrm{~mm} / \mathrm{năm}$.

- Thành phần loài thực vật nơi Hoàng liên ô rô lá dày phân bố tương đối đơn giản, loài cây này mọc chủ yếu với những cây bụi vàng thảm tươi, tầng cây gỗ chiếm tỷ lệ rất thấp.

\section{Lời cảm ơn}

Nghiên cứu này được tài trợ bởi Viện Hàn lâm khoa học và công nghệ Việt Nam (Mã số đề tài: VAST.ĐLT.04/15-16) và Quỹ Phát triển khoa học và công nghệ Quốc gia NAFOSTED (mã số đề tài: 106-NN.032016.49).

\section{Tài liệu tham khảo}

[1] Võ Văn Chi (2012), Từ điển cây thuốc Việt Nam, Nxb Y học, Hà Nội.

[2] Đỗ Tất Lợi (2000), Những cây thuốc và vị thuốc Việt Nam, Nxb Y học, Hà Nôi.

[3] Flora of China Editorial Committee (2001), Flora of China, Vol. 19, p.778

[4] Nguyễn Tiến Bân (1997), Cẩm nang tra cứu và nhận biết các họ thực vật hạt kín ở Việt Nam, Nxb Nông nghiệp, Hà Nội.

[5] Nguyễn Tiến Bân (chủ biên) (2003), Danh lục các loài thực vật Việt Nam, tập 2, Nxb Nông nghiệp, Hà Nội.

[6] Bộ Khoa học và Công nghệ- Viện Khoa học và Công nghệ Việt Nam (2007), Sách đỏ Việt Nam, phần II, Nxb Khoa học tự nhiên và Công nghệ.

[7] Nguyễn Bá Ngãi (1999), Phương pháp đánh giá nông thôn, Bài giảng chuyên đề Lâm nghiệp xã hội, Trường Đại học Lâm nghiệp, Hà Nội.

[8] Nguyễn Nghĩa Thìn (2007), Các Phương pháp nghiên cứu thực vật, $\mathrm{Nxb}$ Đại học quốc gia Hà Nội.

[9] Nguyễn Thượng Dong, Bùi Thị Bằng, Nguyễn Kim Cẩn, Phạm Thanh Kỳ, Vũ Ngọc Lộ, Nguyễn Tập, Phạm Văn Thanh, Nguyễn Bích Thu, Nguyễn Duy Thuần, Nguyễn Văn Thuận (2006), Nghiên cứu thuốc từ thảo dược, $\mathrm{Nxb}$ Khoa học và Kỹ thuật, Hà Nội.

[10] Gary J. Martin (1995), Ethnobotany, a methods manual, Chapman \& Hall, UK.

[11] Hoàng Chung (2009), Các phương pháp nghiên cứu quần xã thực vật, $\mathrm{Nxb}$ Giáo Dục. 


\title{
Biological and Ecological Characteristics of Mahonia bealei (Fortune) Pynaert in Vietnam
}

\author{
Bui Van Huong ${ }^{1}$, Ngo Duc Phuong ${ }^{2}$, Nguyen Trung Thanh ${ }^{2}$ \\ Tran Van $\mathrm{Tu}^{3}$, Nguyen Thai Son ${ }^{3}$, Nguyen Thi Van $\mathrm{Anh}^{4}$, Bui Van Thanh ${ }^{4}$ \\ ${ }^{1}$ Vietnam National Museum of Nature, Vietnamese Academy of Science and Technology, \\ 18 Hoang Quoc Viet, Hanoi, Vietnam \\ ${ }^{2}$ Faculty of Biology, VNU University of Science, 334 Nguyen Trai, Hanoi, Vietnam \\ ${ }^{3}$ Hoang Lien National Park \\ ${ }^{4}$ Institute of Ecology and Biological Resources, Vietnamese Academy of Science and Technology, \\ 18 Hoang Quoc Viet, Hanoi, Vietnam
}

\begin{abstract}
Mahonia bealei (Fortune) Pynaert) is a value medicinal plant and has natural distribution in Bat Xat and Sa Pa distr., Lao Cai province; Quan Ba distr., Ha Giang province. This species is heavily exploited by local people and will be exhausted in the future. Study on biological and ecological characteristics has special importance in conservation and development. Our results showed that Mahonia bealei is shurbs, 0,5-2(-4)m tall, leaves imparipinnate, $25-40 \times 8 \times 13 \mathrm{~cm}$, with 8-14 pairs of leaflets, margin leaflets has sharp teeth. Inflorescence erect with 3 - 9 yellow fascicled. Berry, olivary, 1 - 2 seeds in each fruit. Mahonia bealei are often growth in July to October, each times $11,73 \mathrm{~cm}$ high; It usually grows under the canopy of open forests or scrubs on limestones, where have little humus and food value is very poor, with $1.700-2.500 \mathrm{~m}$ height, average temperature of $15-16^{\circ} \mathrm{C}$, air humidity above $80 \%$, and rainfall of $1.800-2.800 \mathrm{~mm}$ on each year.
\end{abstract}

Keywords: Mahonia bealei, medicinal plant, Biological, Ecological. 